\title{
Cheap type solar bioclimatic individual houses for residential areas
}

\author{
Teofil Mihailescu ${ }^{*}$, a \\ "Transilvania" University of Brasov, Brasov, Romania
}

\begin{abstract}
In the Romanian architectural practice for individual houses in residential areas, designing the architectural object in order to function together with the nature is neglected in the majority of the situations. This happens despite of a great variety of the solar bioclimatic solutions materialized in the traditional houses of all the Romanian geographical regions in a history of over 2000 years of traditional architecture. Unfortunately, in the local real estate realities, other choices are preferred in instead those of the solar bioclimatic architecture. The approach starts with a historical approach, analyzing several examples of traditional houses from all the regions of Romania, in order to identify the traditional bioclimatic solutions used to better adapt to the environment. This constitutes the source of inspiration for the modern cheap type solar bioclimatic houses presented. But a way of thinking should be changed for it, with the help of the Romanian state transformed in financial and legislative realities. These cheap type solar bioclimatic individual houses are destined for the middle class families and involve minimum costs for building and living, creating the best premises to efficiently use one or all of the complementary systems for producing, storage and/or transforming the energy from the environment (using solar, wind, water and/or earth energy).
\end{abstract}

\section{Premises, historical and contemporary context, problems}

In the Romanian architectural practice regarding the investments in individual houses in new residential areas, designing the architectural object in order to function together with the nature is neglected in the majority of the situations. This is related to three main factors: a certain reticence of the clients to live in a solar bioclimatic house, a design process ignoring "by default" the conditionings of the solar bioclimatic architecture, and the absence of a real financial help from the state for complementary systems creating energy from natural and clean sources, otherwise very expensive.

This happens despite of a great variety of the bioclimatic solutions materialized in the traditional houses of all the Romanian geographical regions in a history of over 2000 years of traditional architecture adapted to the environment. All the houses have the same main characteristics: an "open" facade towards South also using the roof to have complete shadow in the summer, an almost blind facade towards North, local building materials, a simple compact form, function and volume, an efficient insulation

\footnotetext{
* e-mail: t.mihailescu@unitbv.ro

a Present address: Str. Jepilor, nr. 50, bl. B50, sc. A, et. V, ap. 22, cod 500292, Brasov, Romania.
}

(against water, cold, heat and wind), a smart way of using the vegetation in the site and in relation with the architectural object, etc. Above all the local differences, they all demonstrate what Konrad Lorenz called "convergent adaptation": same response to the same situations (Figs. 1-3).

Despite of this historical context, in the nowadays local real estate realities, other choices are made and other materials are preferred (an architecture of representation more than one of the economy, an architecture as a manifest of the architects' dreams but not of the real needs of the regular medium class clients, incorrect orientations in site, etc.) instead those suitable for the solar bioclimatic architecture. In the present, if there is an interest of the owners of a wrong designed house to "live together" with the nature, this is realized with means that could be called complementary, solving effects but not the causes. But such investments are efficient only if the complementary systems for producing, storage and/or transforming the energy from the environment work together with the solar bioclimatic architecture.

\section{Proposal: invariants and architectural projects}

The approach starts from the premises that could be realized real estate investments with cheap type solar bioclimatic individual houses, designed by respecting the principles of the solar bioclimatic architecture and using in 


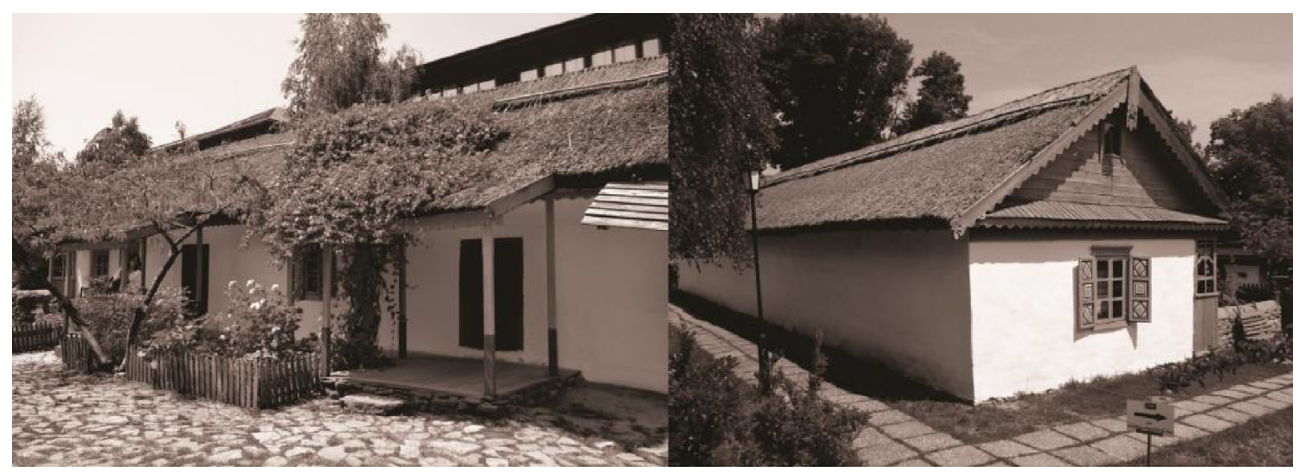

Fig. 1. A traditional house from Jurilovca, Tulcea, XIX-th Century (South-Eastern Romania).

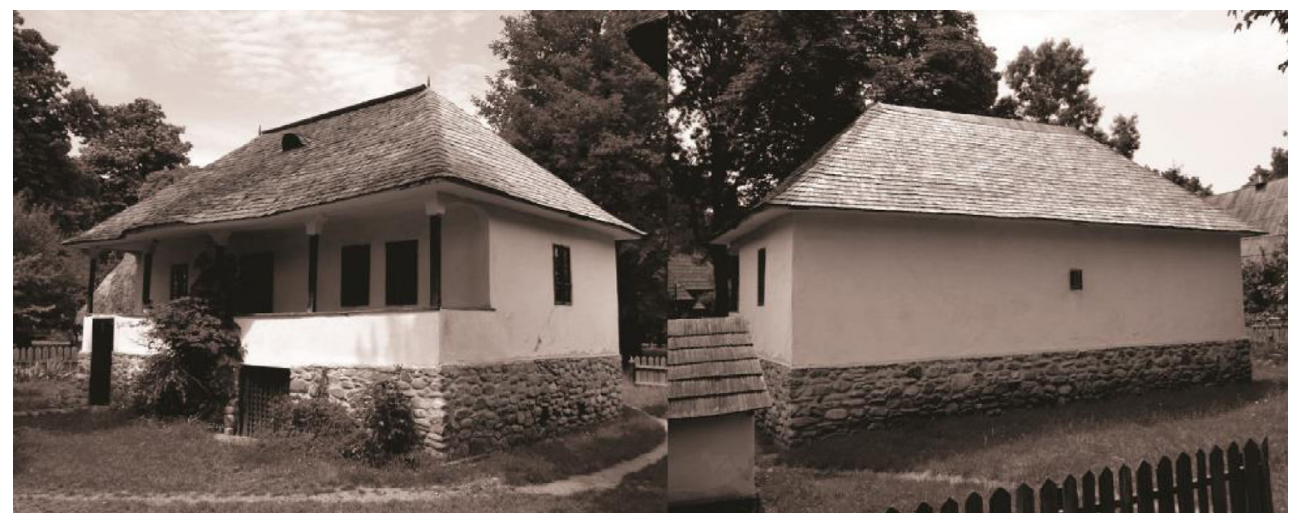

Fig. 2. A traditional house from Stanesti, Arges, XIX-th Century (Center Romania).

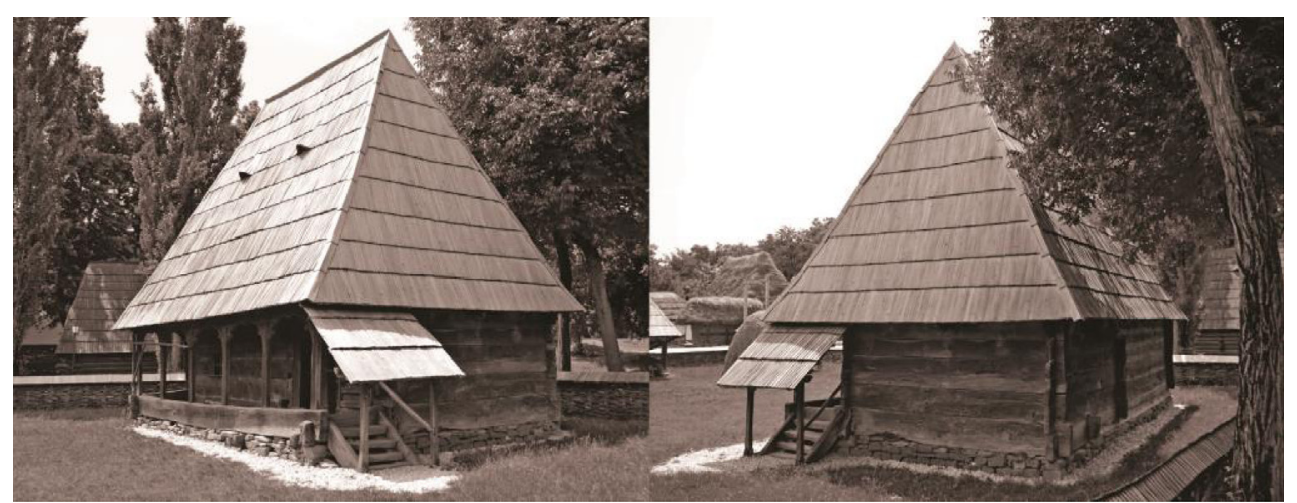

Fig. 3. A traditional house from Berbesti, Maramures, XIX-th Century (Northern Romania).

the most efficient way the complementary systems for producing, storage and/or transforming the energy from the environment (solar, wind, water and/or earth energy). The cheap type solar bioclimatic individual houses presented are destined for the middle class families.

The main invariants in designing the cheap type solar bioclimatic individual houses are: an orientation in site facing South with the main facade, the use of the sun angles related to the geographical position of the site for "negotiating" the shadows, proper and local building materials, a compact architectural form, function and volume, an efficient insulation (against water, cold, heat and wind), a smart way of using the vegetation in the site and in relation with the architectural object, etc.

The goal is to be as close as possible to the Passivhaus German Standard of a heating need less than $15 \mathrm{kWh} /$ $\mathrm{sqm} /$ year and of a final energy need less than $50 \mathrm{kWh} / \mathrm{sqm} /$ year. Above all these invariants the concept is to have a compact, cheap, bioclimatic house, ready to offer the socalled "plan B". 


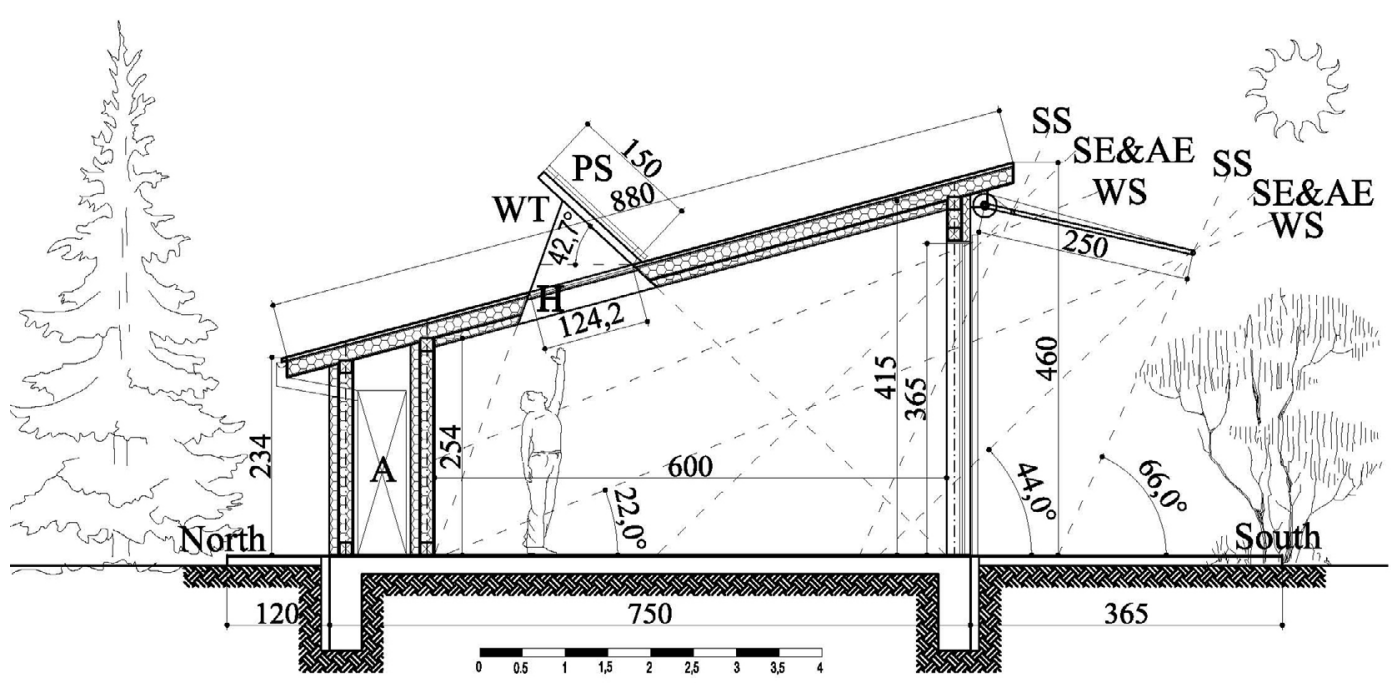

Fig. 4. General demonstrative section for the cheap type solar bioclimatic houses.

\subsection{Context: orientation, site, sun angles, vegetation}

The houses are designed for the geographical and climatic parameters of Brasov, Romania: latitude: +45.66 $\left(45^{\circ} 39^{\prime} 36^{\prime \prime} \mathrm{N}\right)$, longitude: +25.61 $\left(25^{\circ} 36^{\prime} 36^{\prime \prime} \mathrm{E}\right)$, time zone: $\mathrm{UTC}+2 \mathrm{~h}$, altitude $\sim 540 \mathrm{~m}$, temperature variation summer/winter $\pm 23{ }^{\circ} \mathrm{C}$. The sun angles are: (a) $19^{\circ}-24^{\circ}$ $\left(22^{\circ}\right)$ at $13.00 \mathrm{~h}$ on December, 21 at the Winter Solstice (WS), with the sunrise at E and sunset at W, (b) $42.5^{\circ}-45^{\circ}\left(44^{\circ}\right)$ at $12.00 \mathrm{~h}$ on March, 21 at the Spring Equinox (SE) and on September, 23 at the Autumn Equinox (AE), with the sunrise at $\mathrm{E}$ and sunset at $\mathrm{W}$, and (c) $66^{\circ}-70^{\circ}\left(66^{\circ}\right)$ at $13.00 \mathrm{~h}$ on June, 21 at the Summer Solstice (SS), with the sunrise at N-E and sunset at $\mathrm{N}-\mathrm{W}[1]$ (Fig. 4).

In order to use at its best the sun energy, the houses should be placed at the North side of the site, to have all the conditions for receiving the biggest amount of (sun) light during the winter months (from 9.00 a.m. to 15.00 p.m.). In this respect, the houses would have the smallest possible facade, minimal openings and secondary interior functions towards North and the biggest facade, maximal openings and the main living areas towards South, in a section designed to use at its best the sun reference angles at solstices and equinoxes. As concern the vegetation of the site, the best scenario is to have a barer of perennial trees (resinous) protecting from the winter winds from North, and a barer of seasonal vegetation at South protecting from the summer sun and offering it in the winter).

\subsection{Concept: plans, volumes, function, materials}

The cheap type solar houses concept is simple, based on economy and modesty. The architectural expression is given by its linear South facade. The self-imposed conditions of the concept are: the solar architectural principles and efficient display for the complementary systems for producing, storage and/or transforming the energy from the environment. Each house is made of wood, built on a concrete foundation. The houses are insulated by a minimum of $25 \mathrm{~cm}$ of thermo insulation (the efficiency goal: $\left.U \leq 0.15 \mathrm{~W} /\left(\mathrm{m}^{2} \mathrm{~K}\right)\right)$. The roof has a $15^{\circ}$ slope towards North, for a minimum shadow of the house and the use of snow as an extra insulation during the winter. The windows and doors have three rows of glass of 3-4 mm, in a panel with inert gas (the efficiency goal: $\left.U \leq 0.80 \mathrm{~W} /\left(\mathrm{m}^{2} \mathrm{~K}\right)\right)$, and exterior extra protection for winter with mobile insulated panels $(G)$ reducing the loss of heat [2].

The houses presented have also a symbolic dimension: lots of the interior spaces are dimensioned using the golden proportion, the height of the South windows and the width of the front terrace have $365 \mathrm{~cm}$ (the number of the days in a year), the rooms for the children are at East (future, sunrise) and the matrimonial bedroom at West (past, sunset) as each day starts with its symbolically birth at the sunrise and ends with its symbolically death at the sunset.

\subsection{Heating, ventilation, water, electric power}

The heating for the solar bioclimatic house is realized both passive and active. The premise is that the entire volume is almost perfect isolated.

\subsubsection{Heating}

The passive heating, this is realized using the windows, using the dark interior pavement of the concrete foundation to store the heat from the sun and release it during the night (as it is exposed to the sun in 50-80\% of its surface), and using the additional heat generated by the house electric equipments. In the good sunny winter days, $50-75 \%$ of the total heat requirements of the house can be supplied this way [3]. For the rest of the time, the house uses: traditional tiled/glazed stoves positioned to heat two spaces (D), a chimney (E), and/or natural gas as alternative. In the bathrooms, the heating and the hot water could be provided by a little iron traditional heating stoves with a water boiler (C) using an insignificant quantity of wood. 


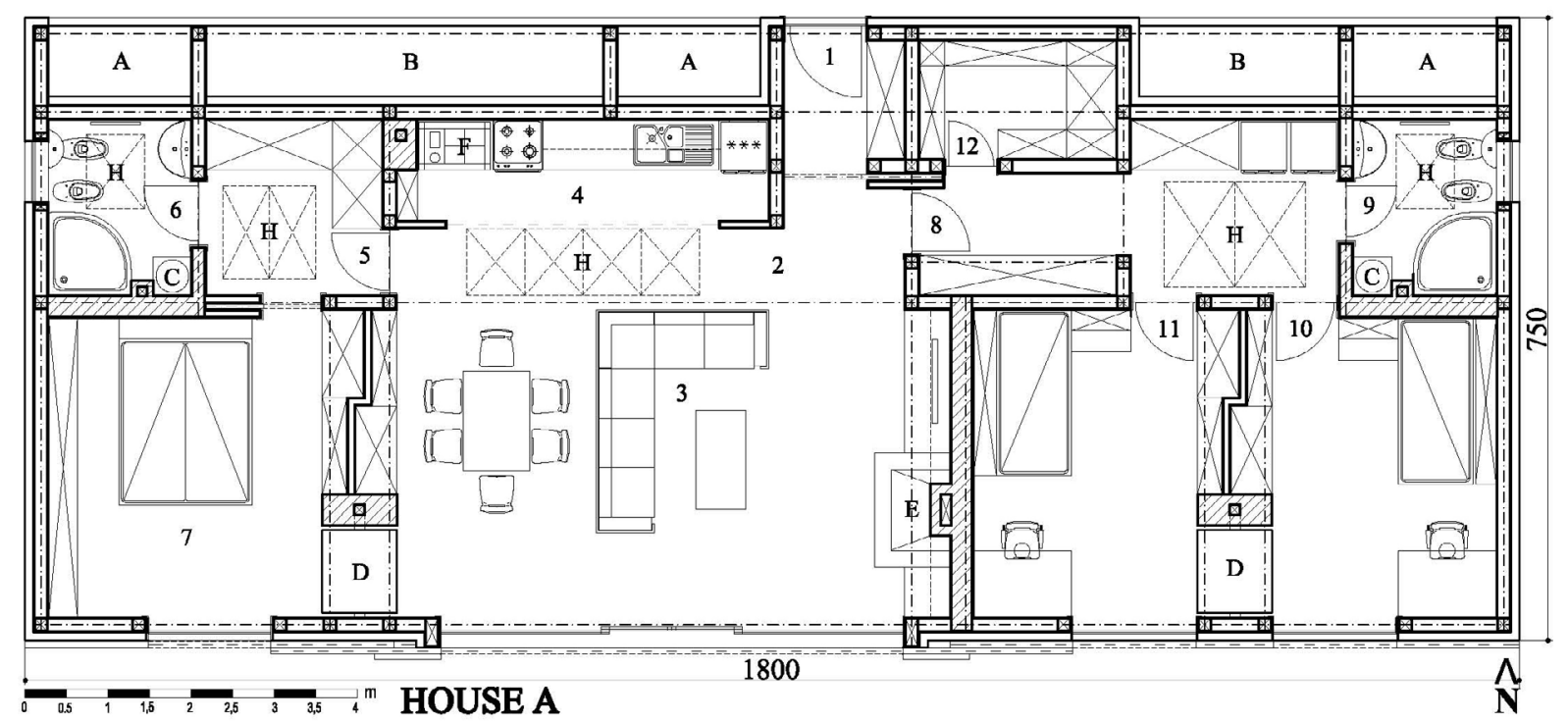

Fig. 5. Plan of House A.

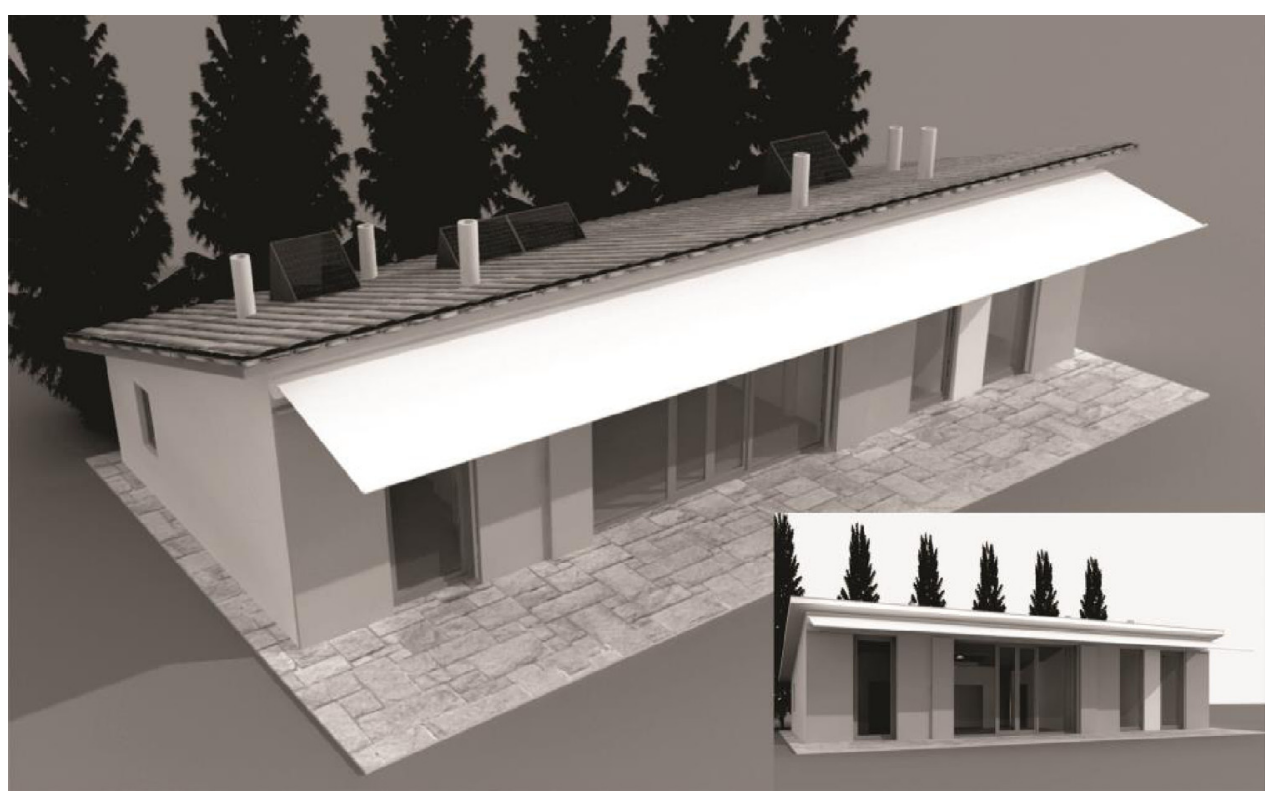

Fig. 6. Perspectives of House A.

The efficiency of the heating works together with the efficient insulation. The houses use both free natural ventilation (the series of the roof windows $(\mathrm{H})$ as "wind tunnels" (WT) [4] in spring-summer-autumn) and electric ventilation with heat recuperating systems in winter, for a refreshed air volume of $\sim 30 \mathrm{~m}^{3} / \mathrm{h} /$ person.

\subsubsection{Water}

The house tends to use drink water only for the human subsistence and the rainwater collected from the roof for other activities. The water tanks (A) are nearby the bathrooms and kitchen and the process is gravitational. Heated water is produced as much as possible by solar systems [5].

\subsubsection{Electric power}

The electric power is partially produced by photovoltaic systems (PS) [6] and/or by small turbines using the wind power [7]. The windows on the South facade and on the roof $(\mathrm{H})$ provide the natural light and the led technology provides the artificial light. The house is equipped with electric equipments of energy class A or superior. 


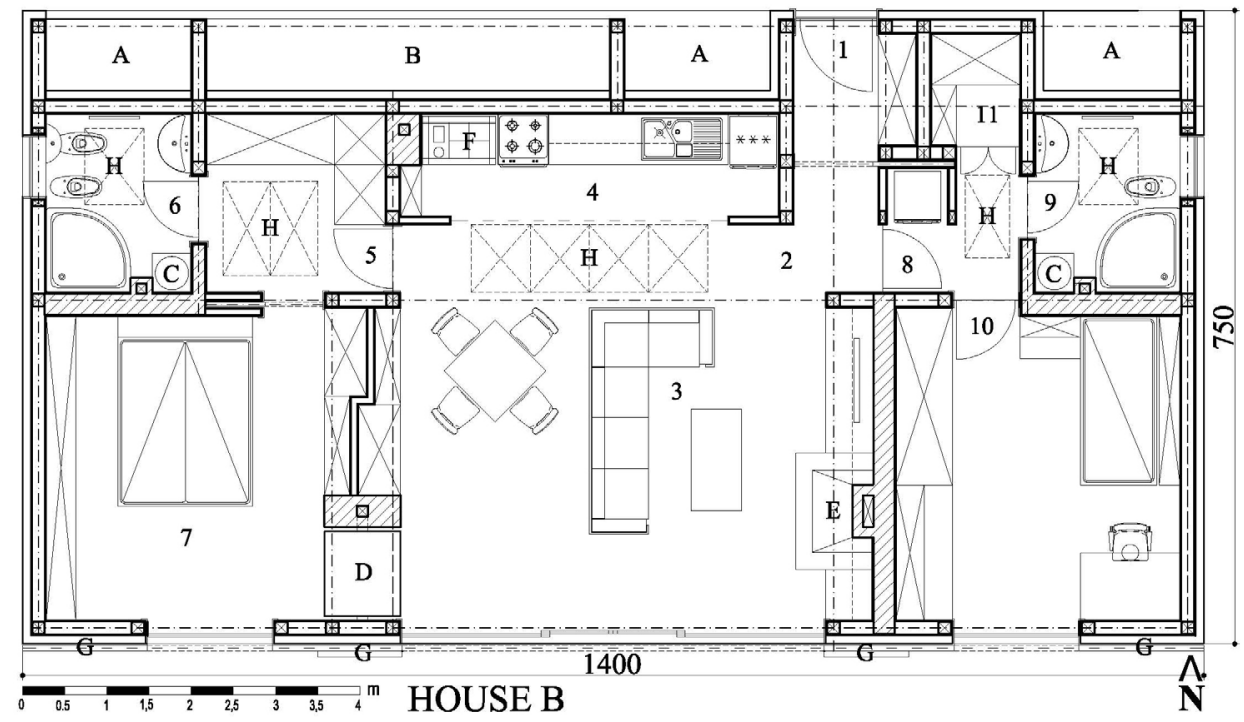

Fig. 7. Plan of House B.

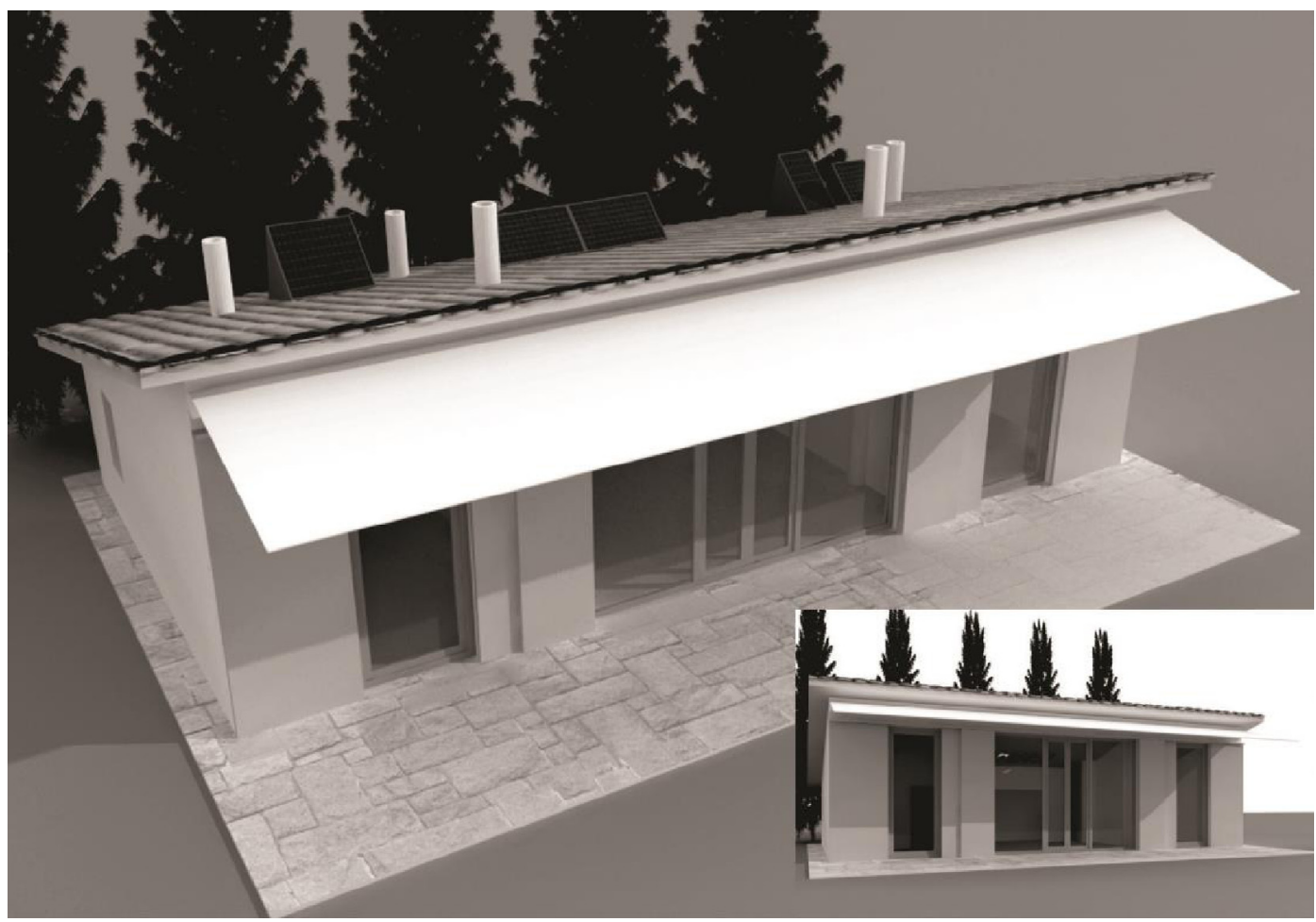

Fig. 8. Perspectives of House B.

\subsection{The three cheap type solar bioclimatic individual projects: Houses A, B and C}

The estimated price for building such a house at the Romanian prices for the basic building materials, (stone, brick, wood, concrete, etc.), using local resources and local small scale building companies is about 250 euro/sqm. The houses are not prefabricated but realized by local constructors. The building solutions are simple and easy to be realized. The projects are type projects therefore very cheap.

\subsubsection{House A}

It is a house designed for a family with two adults and two children, and has a total built area of $135 \mathrm{sqm}$, of which $94 \mathrm{sqm}$ for living. Of a total of $74.70 \mathrm{sqm}$ of the South facade, $36.50 \mathrm{sqm}$ are windows $(48.86 \%)$. The house has: access wind fang (1), circulations $(2,5$, and 8$)$, living room and dining (3), kitchen (4), matrimonial bedroom (7), bathrooms $(6,9)$, rooms $(10,11)$, a pantry $(12)$. At North is designed the storage space for wood (B) of $6 \mathrm{sqm} / 15.20$ 


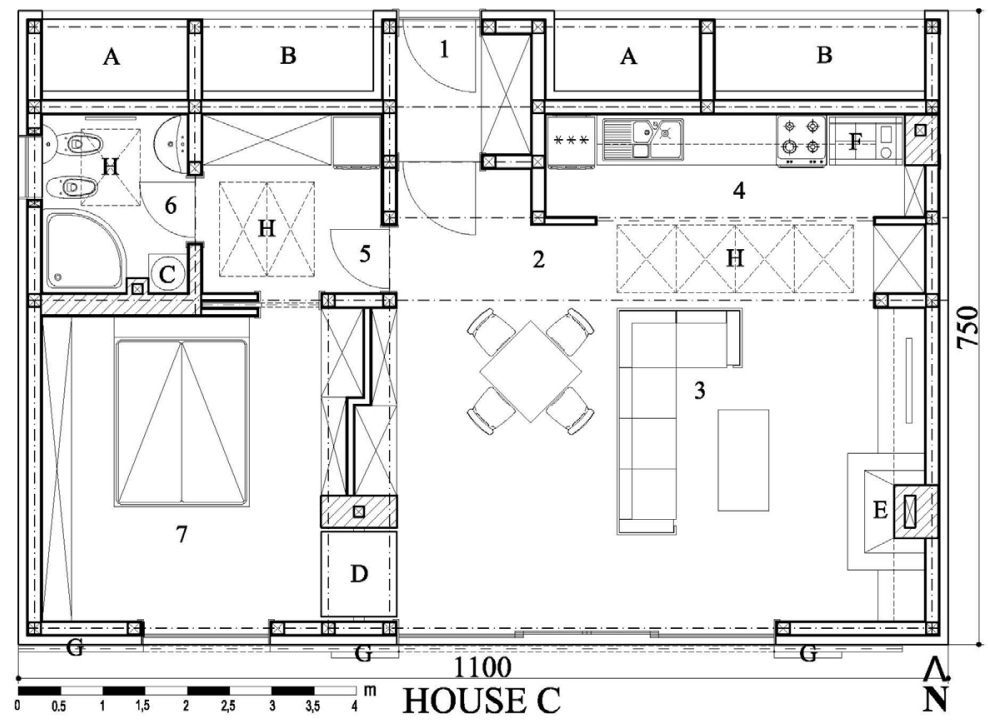

Fig. 9. Plan of House C.

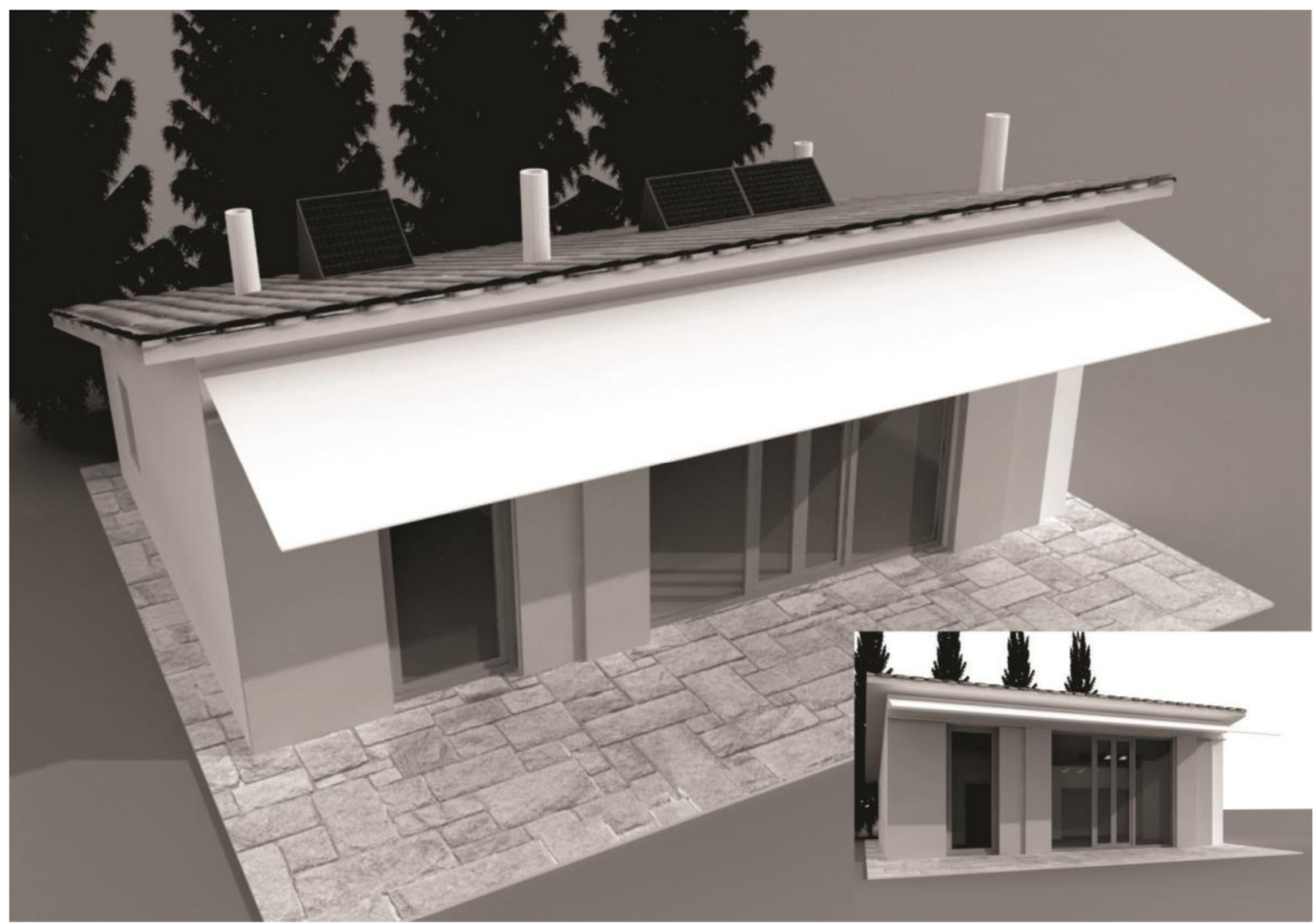

Fig. 10. Perspectives of House C.

cubic meters, and the space for water tanks (A) of $4.35 \mathrm{sqm} / 9.50$ cubic meters, collecting water from the roof (Figs. 5 and 6).

\subsubsection{House $B$}

It is a house designed for a family with two adults, one child, having a total built area of $105 \mathrm{sqm}$, of which $79 \mathrm{sqm}$ for living. Of a total of $58.10 \mathrm{sqm}$ of the
South facade, $29.05 \mathrm{sqm}$ are windows $(50.00 \%)$. The house has: access wind fang (1), circulation spaces $(2,5$, and 8), living room and dining (3), kitchen (4), matrimonial bedroom (7), bathrooms $(6,9)$, a room (10), a pantry (11). At North the house has a storage space for wood (B) of $4.05 \mathrm{sqm} / 10.12$ cubic meters, and a space for water tanks (A) of $4.35 \mathrm{sqm} /$ 9.50 cubic meters, collecting water from the roof (Figs. 7 and 8). 


\subsubsection{House C}

It is a house designed for a family with 2 members. It has a total built area of $82.50 \mathrm{sqm}$, of which $62 \mathrm{sqm}$ for living. Of a total of $46.65 \mathrm{sqm}$ of the South facade, $21.68 \mathrm{sqm}$ are windows (46.47\%). The house has: circulation spaces $(1,2$, and 5$)$, living room and dining (3), kitchen (4), matrimonial bedroom (7), bathroom (6). At North the house has the storage space for wood (B) of $4.05 \mathrm{sqm} / 10.12$ cubic meters, and for the water tanks (A) of $2.90 \mathrm{sqm} / 6.38$ cubic meters (Figs. 9 and 10).

\section{Conclusions}

Above all, the solar bioclimatic architecture involves a way of life. But an entire way of thinking should be changed for it, involving a change of paradigm in mentalities and the help of the professionals, media and of the government for the urban actors to be motivated in making bioclimatic architecture in respect for the sustainable development principles [8]. The main premises in designing these cheap type solar bioclimatic individual houses are: to learn from the history of the traditional Romanian architecture, to accept a way of life involving a set of principles of solar bioclimatic architectural design, to optimize the relation between the natural and built environment in order to maximize the efficiency in using the thermo energy, and economy and efficiency in all the aspects of the life lived in a solar bioclimatic house (form, function, building materials, equipments, living space, energy, etc.) as a sustainable way of life offering also the chance of a relative or almost complete independence (the famous "plan B"). Living in a cheap solar bioclimatic individual house means choosing a way of life. Living in a cheap solar bioclimatic individual house is a statement. In a solar bioclimatic house are integrated both traditional adaptive solutions offering protection from elements (sun, water, wind, snow, dust, cold, heat), and modern solutions translated in simple, cheap and efficient building/insulation materials and complementary technological systems for producing clean/green energy. In this respect, the architecture of the cheap type solar bioclimatic individual houses means a neutral and simple so-called "extruded box", apparently lost in the nature and open to the South sky as an intermediate between humans and environment.

\section{References}

1. For the sun path diagram and energy, the sunrise/sunset/ dusk/dawn time table, the surface meteorology: http://www. gaisma.com/en/dir/ro-country. For information about astronomy see: www.astro-urseanu.ro

2. All of the four houses have integrated storage spaces, displaying and functional spaces

3. P. Guedes, The Macmillan encyclopedia of architecture and technological change (The Macmillan Press Ltd., London, 1979), pp. 224-225

4. P. Guedes, The Macmillan encyclopedia of architecture and technological change (The Macmillan Press Ltd., London, 1979), pp. 12-13

5. A.-M. Dabija, S. Gheorghe, A. Mortu, L. Buzatu, Sisteme fotovoltaice in arhitectura (Editura Universitara "Ion Mincu", Bucuresti, 2010), pp. 43-44

6. F. Antony, C. Durschner, K.-H. Remmers, Photovoltaics for professionals: solar electric systems marketing, design and installation (Solarpraxis AG, Germany, 2007)

7. http://saferenvironment.wordpress.com/2008/11/03/windenergy-renewable-energy-harnesses-natural-wind-power- $\%$ E2\%80\%93-effective-answer-for-emission-problem-towardscleaner-safer-and-greener-environment

8. For the sustainable development see: http://architecture. about.com/od/greenconcepts/g/sustainable.htm

Cite this article as: Teofil Mihailescu, Cheap type solar bioclimatic individual houses for residential areas, Renew. Energy Environ. Sustain. 1, 7 (2016) 